\title{
Erratum to: A plasticity model for sand-structure interfaces
}

\author{
A. Lashkari \\ Department of Civil \& Environmental Engineering, Shiraz University of Technology, Shiraz 71555-313, Iran
}

(C) Central South University Press and Springer-Verlag Berlin Heidelberg 2012

Erratum to: J. Cent. South Univ. (2012) 19: 1098-1108

DOI: $10.1007 / \mathrm{s} 11771-012-1115-1$

The original version of this article unfortunately contained a mistake. The equation (16) was incorrect. The corrected equation is given below.

$M^{\mathrm{d}}=M\left[1-n_{\mathrm{d}} \ln \left(\sigma_{\mathrm{nc}} / \sigma_{\mathrm{n}}\right)\right]$ 